\title{
Ecosystem turnover in palaeoecological records: the sensitivity of pollen and phytolith proxies to detecting vegetation change in southwestern Amazonia
}

Article

Accepted Version

Plumpton, H., Whitney, B. and Mayle, F. (2019) Ecosystem turnover in palaeoecological records: the sensitivity of pollen and phytolith proxies to detecting vegetation change in southwestern Amazonia. The Holocene, 29 (11). pp. 17201730. ISSN 1477-0911 doi:

https://doi.org/10.1177/0959683619862021 Available at https://centaur.reading.ac.uk/83798/

It is advisable to refer to the publisher's version if you intend to cite from the work. See Guidance on citing.

To link to this article DOI: http://dx.doi.org/10.1177/0959683619862021

Publisher: SAGE

All outputs in CentAUR are protected by Intellectual Property Rights law, including copyright law. Copyright and IPR is retained by the creators or other copyright holders. Terms and conditions for use of this material are defined in the End User Agreement. 


\section{www.reading.ac.uk/centaur}

\section{CentAUR}

Central Archive at the University of Reading

Reading's research outputs online 


\title{
Ecosystem turnover in palaeoecological records: The sensitivity of pollen and phytolith proxies to detecting vegetation change in southwestern Amazonia
}

\author{
Authors: Heather Plumpton ${ }^{a *}$, Bronwen Whitney $^{b}$, Francis Mayle ${ }^{a}$ \\ Author affiliations: \\ aDepartment of Geography and Environmental Science, University of Reading, UK

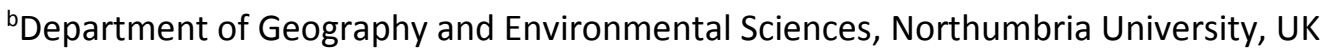 \\ *corresponding author. Email address: hjplumpton@gmail.com
}

\begin{abstract}
Identification of ecosystem turnover in the palaeo-vegetation record is important for understanding the resilience of ecosystems to past environmental change. There is uncertainty over the ability of different types of palaeo-vegetation proxy to detect ecosystem turnover. The aim of this paper is to compare the sensitivity of two palaeo-vegetation proxies - pollen and phytoliths - to changes within and between three key tropical South American ecosystems: evergreen forest, dry forest and savannah. A quantitative approach is used to assess the sensitivity of these two proxies to vegetation changes, based on the variability of proxy assemblages from 1-hectare ecological plots in ecotonal south west Amazonia. This modern dataset of proxy variability within evergreen forest, dry forest and savannah plots is then used to define thresholds for proxy variability which differentiate floristic changes within an ecosystem from ecosystem turnover. These thresholds are applied to two palaeo-vegetation records from NE Bolivia. Our results show that pollen is more sensitive than phytoliths to changes within evergreen forest, but phytoliths are more sensitive than pollen to changes within dry forest. Both proxies were equally sensitive to changes within savannas. These are important considerations for palaeoecologists selecting proxies for the study of ecosystem turnover in the palaeo-record. Application of the thresholds to the palaeo-record demonstrated the utility of this quantitative approach for assessing the magnitude of vegetation change in the palaeo-record. This quantitative approach is therefore a useful tool to improve the identification of ecosystem turnover in the palaeo-record.
\end{abstract}

\section{Keywords}

Ecosystem turnover, variability, thresholds, pollen, phytoliths, south-west Amazonia, evergreen forest, dry forest, savannah, palaeoecology

\section{Introduction}

Ecosystem turnover is the process whereby one ecosystem is replaced by another, either in space or time (Holling, 1973). For example, under drier climatic conditions a tropical rainforest may be 
replaced by savannah. The process of ecosystem turnover is a key area of ecological research for understanding the resilience of ecosystems to climatic change and for identifying tipping points between alternative states, such as humid forest and savannah (Scheffer et al., 2009). This area of research has gained particular attention due to the proposal of planetary boundaries beyond which the earth system will be outside the safe operating space for humanity (Mace et al., 2014; Rockström et al., 2009). Palaeoecology has an important contribution to make to this area of research through the identification of ecosystem turnover and contributory environmental factors in the palaeo-record (see questions 16 and 17 in Seddon et al., 2014). For example, the latest IPCC report on $1.5^{\circ} \mathrm{C}$ of warming uses three palaeo time periods (Holocene Thermal Maximum, Last Interglacial, Mid Pliocene Warm Period) as analogues of warmer periods when feedbacks in the earth system led to ecosystem turnover including retreat of tropical forests and expansion of savannah (Dowsett et al., 2016).

The conventional approach to identifying ecosystem turnover in the palaeo-record is through qualitative interpretation of pollen and other palaeo-vegetation and -environmental proxies. A more quantitative approach is to use the variability in pollen records as an indicator of ecosystem turnover; the more variable the record, the more likely vegetation change is taking place (Overpeck et al., 1985). This approach has been used in temperate and tropical regions to identify periods of high vegetation turnover in the pollen record and their relation to climatic changes (Bush et al., 2004; Seddon et al., 2015; Shuman and Newby, 2009; Urrego et al., 2009). Variation in the pollen record is measured through calculation of multivariate distance between pollen assemblages through time. Multivariate distance takes both the number and abundance of pollen taxa into account and gives a measure of the "difference" between two pollen assemblages (Legendre and Birks, 2012; Legendre and Gallagher, 2001). A large distance indicates a large difference between two pollen assemblages and hence a difference in the parent vegetation (Grimm and Jacobson, 1992; Overpeck et al., 1985; Seddon et al., 2015; Shuman et al., 2005). If this variation in the vegetation is significant, it could represent replacement of one ecosystem by another; i.e. ecosystem turnover. Therefore, the magnitude of variation in the pollen record gives an indication that ecosystem turnover may be taking place.

Additionally, the choice of palaeo-vegetation proxy may be important, as different proxies may differ in their sensitivity to ecosystem turnover. Alongside pollen, phytoliths are becoming an important palaeoecological proxy in the Neotropics as they have been shown to differentiate tropical ecosystems such as evergreen forest, dry forest and savannah (Dickau et al., 2013; Watling et al., 2016). This ability suggests they would be sensitive to turnover between these ecosystems, but their relative sensitivity compared to pollen is poorly understood. As most plant taxa cannot be identified to the same taxonomic resolution by both pollen and phytoliths, it is not possible to compare the sensitivity of the two proxies to floristic changes within ecosystems based on individual indicator taxa. Therefore, to directly compare the two proxies, it is necessary to use a quantitative approach which standardises the full proxy assemblage. The variation in proxy assemblages indicates the sensitivity of the proxy to vegetation changes in that ecosystem; high variability indicates high sensitivity. This information can be used to inform proxy choice by palaeoecologists studying these ecosystems. Furthermore, analysis of variability in modern pollen and phytolith assemblages provides context and a modern training dataset for identification of periods of high variability representing ecosystem turnover in the palaeo-record. 
Noel Kempff Mercado National Park (NKMNP), NE Bolivia, was chosen as the study site to develop this modern training dataset and compare the sensitivity of pollen and phytoliths to vegetation changes because both modern pollen and phytolith datasets are available from ecological plots from a range of ecosystem types within this park, covering all the major plant communities in south-west Amazonia (evergreen forest, dry forest and savannah) (Burn et al., 2010; Dickau et al., 2013; Gosling et al., 2005, 2009; Jones et al., 2011). These modern pollen and phytolith samples are from within permanent, 1-hectare, vegetation study plots within the RAINFOR network (Malhi et al., 2002; SALVIAS, 2004), which has inventories of all woody stems $>10 \mathrm{~cm}$ d.b.h. This provides a unique opportunity to compare pollen and phytolith assemblages from the same vegetation using a common, quantitative methodology. This is the first direct quantitative comparison of these two proxies.

The aim of this paper is to compare the sensitivity of pollen and phytolith assemblages to changes within and between three key tropical South American ecosystems: humid evergreen rainforest, semi-deciduous dry forest, and terra firme (cerrado) and seasonally-flooded savannah.

The specific questions to be addressed are:

1) Which proxy - pollen or phytoliths - is more sensitive to changes within and between evergreen forest, dry forest and savannah? Does this relationship vary by ecosystem type?

2) What are the implications of proxy variability for reconstructing ecosystem turnover in the palaeo-record? What can this quantitative method of identifying ecosystem turnover add to the traditional qualitative approach?

Here we use a numerical approach to differentiating ecosystem turnover from floristic turnover in palaeo vegetation records between evergreen forest, dry forest and savannah in south west Amazonia. For the purposes of this study, we define floristic turnover as the process of floristic change within an ecosystem, for example an increase in abundance of Anadenanthera trees within a dry forest, and ecosystem turnover as the process of change from one ecosystem to another i.e. dry forest to savannah. A modern training set of phytolith and pollen assemblages from these three key ecosystems is used to quantify the variability in modern assemblages within an ecosystem and between ecosystems. This modern dataset is used to set thresholds for floristic turnover and ecosystem turnover, based on the magnitude of variability in the dataset.

These thresholds are then applied to palaeo-vegetation records from south-west Amazonia, where change from one ecosystem to another has been identified through interpretation of the fossil record. The thresholds assess whether the magnitude of variability in the palaeo-record enables identification of ecosystem turnover at the same horizons as the qualitative interpretation of the record. The pairwise distances between assemblages downcore in the palaeo-record and the full matrix of distances between all assemblages at all depths are compared with the thresholds defined from the modern dataset.

\section{Study area and site selection}

The study area is Noel Kempff Mercado National Park (NKMNP), a $15,230 \mathrm{~km}^{2}$ protected area in north-eastern Bolivia near the southern margin of Amazonia containing a diverse mixture of ecosystems including evergreen forest, semi-deciduous dry forest and savannah (Fig. 1). The east of the park is dominated by upland (cerrado) savannas on the Huanchaca plateau (600-900m a.s.l.), 
while the west of the park beyond the plateau is dominated by evergreen forests, with areas of seasonally inundated savannah near to river courses and small patches of terra firme (cerrado) savannah in raised areas. Towards the south of the park is the ecotone with semi-deciduous dry forest (Fig. 1). The climate is highly seasonal, with a 6-month dry season, annual precipitation between 1400 and $1500 \mathrm{~mm}$, mean annual temperature of $25-26^{\circ} \mathrm{C}$ and occasional cold fronts from Patagonia during austral winter which bring temperatures down to $10^{\circ} \mathrm{C}$ for several days (Killeen and Schulenberg, 1998). The only recent history of human disturbance in the park over the last century is rubber tapping in the early 1900s and low-intensity, selective logging of mahogany prior to the establishment of the national park in 1988 (Killeen and Schulenberg, 1998). This lack of disturbance makes it an ideal site for modern pollen and phytolith studies. Furthermore, a network of permanent vegetation study plots (part of the RAINFOR network) has been set up in and around the park with detailed botanical inventories of each vegetation type (Malhi et al., 2002; SALVIAS, 2004).

[Figure 1 - Map of Noel Kempff Mercado National Park (NKMNP) showing major vegetation communities and location of plots MV1, AC2, CP1, LF1, CH1, CH2, FC1, TO1, FT1. Inset map of South American countries with red-shaded area showing location of NKMNP.]

The evergreen forest ecosystem class contains terra firme evergreen forest at plot LF1 and evergreen liana forest at plots $\mathrm{CH} 1$ and $\mathrm{CH} 2$. The evergreen forest at LF1 is tall, mature and dominated by tall trees such as Pseudolmedia laevis and the arboreal herbaceous plant Phenakospermum guianensis (Gosling et al., 2005). The evergreen liana forest at $\mathrm{CH} 1$ and $\mathrm{CH} 2$ has a low, dense canopy dominated by liana growth (Killeen and Schulenberg, 1998). The semi-deciduous dry forest ecosystem class contains seasonally inundated (plot MV1) as well as terra firme (plots AC2, CP1) forest. The three most abundant species in the terra firme dry forest are Caesalpinia floribunda, Tabebuia roseo-alba, and Anadenanthera colubrina (Gosling et al., 2009). In the seasonally inundated dry forest common taxa include Inga ingoides, Physocalymma scaberimum and Hirtella gracilipes (Dickau et al., 2013). The savannah ecosystem class also contains both terra firme (plot FC1) and seasonally inundated (plots FT1, TO1) communities. Both communities are dominated by Panicoideae grasses, but the terra firme (cerrado) savannah contains Myrtaceae, Borreria sp. and Dilleniaceae, whereas the seasonally inundated savannah contains Cyperaceae, Eriocaulaceae and Xyridaceae (Dickau et al., 2013).

Table 1 - plant community and broad ecosystems for each 1-hectare study plot, number of samples per plot and reference to original publication of raw data. $\mathrm{SI}=$ seasonally-inundated, $\mathrm{TF}=$ terra firme.

\begin{tabular}{|l|l|l|l|l|l|}
\hline Ecosystem & $\begin{array}{l}\text { Plant } \\
\text { community }\end{array}$ & $\begin{array}{l}\text { Plot } \\
\text { code }\end{array}$ & $\begin{array}{l}\text { No. } \\
\text { phytolith } \\
\text { samples }\end{array}$ & $\begin{array}{l}\text { No. } \\
\text { pollen } \\
\text { samples }\end{array}$ & References \\
\hline Dry forest & $\begin{array}{l}\text { SI Dry } \\
\text { forest }\end{array}$ & MV1 & 6 & 4 & $\begin{array}{l}\text { Dickau et al., 2013; Jones et } \\
\text { al., 2009 }\end{array}$ \\
\cline { 2 - 6 } & forest & AC2 & 3 & 4 & $\begin{array}{l}\text { Dickau et al., 2013; Gosling } \\
\text { et al., 2009 }\end{array}$ \\
\cline { 2 - 6 } & CP1 & 3 & 4 & $\begin{array}{l}\text { Dickau et al., 2013; Jones et } \\
\text { al., 2009 }\end{array}$ \\
\hline $\begin{array}{l}\text { Evergreen } \\
\text { forest }\end{array}$ & $\begin{array}{l}\text { TF } \\
\text { Evergreen } \\
\text { forest }\end{array}$ & LF1 & 6 & 7 & $\begin{array}{l}\text { Dickau et al., 2013; Gosling } \\
\text { et al., 2009 }\end{array}$ \\
\hline
\end{tabular}




\begin{tabular}{|l|l|l|l|l|l|}
\hline & $\begin{array}{l}\text { TF Liana } \\
\text { forest }\end{array}$ & $\begin{array}{l}\text { CH1, } \\
2\end{array}$ & 6 & 5 & $\begin{array}{l}\text { Burn et al., 2010; Dickau et } \\
\text { al., 2013 }\end{array}$ \\
\hline Savannah & $\begin{array}{l}\text { TF } \\
\text { Savannah }\end{array}$ & FC1 & 6 & 4 & $\begin{array}{l}\text { Dickau et al., 2013; Jones et } \\
\text { al., 2009 }\end{array}$ \\
\cline { 2 - 6 } & $\begin{array}{l}\text { SI } \\
\text { Savannah }\end{array}$ & FT1 & 3 & 4 & $\begin{array}{l}\text { Dickau et al., 2013; Jones et } \\
\text { al., 2009 }\end{array}$ \\
\cline { 2 - 6 } & TO1 & 3 & 4 & $\begin{array}{l}\text { Dickau et al., 2013; Jones et } \\
\text { al., 2009 }\end{array}$ \\
\hline
\end{tabular}

The first site chosen for application of the ecosystem turnover thresholds to the palaeo-record is Laguna Granja, as it has both pollen and phytolith records for the past 6,000 years (Carson et al., 2015). L. Granja is located $250 \mathrm{~km}$ north-west of NKMNP, at the geological boundary between the Pre-Cambrian Shield which supports terra firme evergreen forest and the sedimentary basin of the Beni region which supports a mosaic of seasonally inundated savannah and forest islands. L. Granja is a small $\left(0.2 \mathrm{~km}^{2}\right)$ oxbow lake surrounded by riparian forest at the lake margins, transitioning to terra firme evergreen forest further away from the lake. A small area $\left(0.3 \mathrm{~km}^{2}\right)$ to the east of the lake has been cleared for agriculture (Carson et al., 2015).

The second site chosen for application of the pollen ecosystem turnover threshold to the palaeorecord is Laguna Chaplin, as it is a well-studied example of ecosystem turnover from savannah to evergreen forest (Burbridge et al., 2004; Mayle et al., 2000). However, only pollen data are available from this site. L. Chaplin is a large (4-6km diameter), flat-bottomed lake situated within NKMNP on Pre-Cambrian Shield bedrock, surrounded by terra firme evergreen forest with areas of riparian forest lining nearby rivers and streams (Burbridge et al., 2004).

\section{Methods}

This paper contains new analyses of previously published datasets (Burn et al., 2010; Dickau et al., 2013; Gosling et al., 2009; Jones, 2009; Jones et al., 2011) that have been utilised with authors' permission (raw data plotted in Figures SI and S2). Field and laboratory methods used by each of these authors are summarised below; see original papers for full details.

\subsection{Field methods}

Permanent 1-hectare $(500 \times 20 \mathrm{~m})$ vegetation study plots from Noel Kempff Mercado National Park (NKMNP) were sampled for pollen rain and soil-surface phytoliths. Pollen rain was collected from artificial pollen traps (Burn et al., 2010; Gosling et al., 2005, 2009; Jones et al., 2011) and phytoliths were sampled from the soil layer underlying the soil leaf litter layer (Dickau et al., 2013). Sample collection was evenly spaced along a central transect through each plot. The ten pollen samples per plot were spaced 50m apart (Gosling et al., 2005) and the three phytolith samples per plot were $250 \mathrm{~m}$ apart (Dickau et al., 2013). The spatial variability of pollen rain within terra firme evergreen forest plots was found to be high for some taxa (Hyeronmia, Trema, Cecropia, Didymopanax) and for Pollen Accumulation Rates (PARs). However, all samples were still dominated by Moraceae/Urticaceae, and there was no discernible bias in the pollen variability towards the taxon of the nearest tree. The majority of the spatial variability within the plots was captured by analysis of five of the ten pollen trap samples (Gosling et al., 2005). The samples used in this analysis are a 
subset of the full published datasets. The plots chosen for this analysis were selected based on the availability of both pollen and phytolith datasets; only plots with both datasets were included in the analysis. The nine plots that met these criteria span six plant communities and three ecosystem classes (Table 1). Twelve samples from within each ecosystem class were selected from the full published datasets. Samples were chosen to reflect an even distribution between different plant communities within each ecosystem class e.g. terra firme and seasonally-inundated savannas. Within plots, samples were chosen to represent an even spatial distribution within each plot (Table 1).

Detailed vegetation inventories of forest plots record all taxa representing $>1 \%$ of the total number of stems $>10 \mathrm{~cm}$ d.b.h. (Burn et al., 2010; Gosling et al., 2005, 2009). These inventories do not capture understorey grasses, vines or small lianas. For the savannah plots, horizontal ground cover of each plant along line transects were recorded, full details on the SALVIAS and RAINFOR databases (Malhi et al., 2002; SALVIAS, 2004).

\subsection{Laboratory methods}

Pollen trap samples were processed using the 'wash' methodology and prepared for microscopy. Details of the methodology are available in the original publications (Burn et al., 2010; Gosling et al., 2009; Jones et al., 2011). Pollen identification was carried out using the Neotropical pollen reference collection of over 1000 species held at the Universities of Leicester and Edinburgh and published pollen atlases (Colinvaux et al., 1999; Roubik and Moreno, 1991). Phytoliths were extracted from $100 \mathrm{ml}$ of soil using the wet oxidation protocol (Piperno, 2006). Phytolith identification was carried out using published references and the Neotropical phytolith collection of over 500 species held at the University of Exeter Archaeobotany Laboratory (Dickau et al., 2013).

\subsection{Numerical analysis}

The data were summarised to ecosystem level, i.e. evergreen forest, dry forest and savannah, as these are the most useful vegetation classifications for application to the palaeo-record. 12 samples from each ecosystem were selected from the full published datasets to ensure a consistent number of comparisons between assemblages within each ecosystem (Table 1). Taxonomic classifications in the pollen data were harmonised between datasets from different authors to a common standard. For example, all Moraceae and Urticaceae genera were grouped into one category, as some datasets did not differentiate the constituent genera. For the phytolith data, only A-fraction counts were used to enable comparison to samples from lake sediment where there is often insufficient material available to fractionate the samples into different size classes during preparation. The calculations of variability in these assemblages are therefore conservative, as variability in palaeo-records is likely to be higher given the higher diversity of classifications.

The Hellinger transformation was applied to harmonised pollen and phytolith data before Euclidean distances between all pollen assemblages and between all phytolith assemblages were calculated using vegan 2.5-2 in R 3.5.0 (Oksanen et al. 2018). This method is equivalent to calculation of Hellinger distances, which reduce the influence of zero abundance samples (Legendre and Birks, 2012; Legendre and Gallagher, 2001). Boxplots of distances within each plot and within each ecosystem (including distances within plots and between plots in the same ecosystem) and between ecosystems for pollen and phytoliths were created using the base boxplot function in R 3.5.0. A oneway ANOVA (Distance Ecosystem) was used to determine if the distances within ecosystems were 
significantly different between the ecosystems. TukeysHSD was used to determine which ecosystems were significantly different to each other. Principal Component Analysis (PCA) was carried out on the fossil and modern datasets to assess if the modern samples are suitable analogs for the fossil samples. PCAs were produced using vegan 2.5-2 in R 3.5.0 (Oksanen et al. 2018).

Lower quartile (Q1), median (Q2) and upper quartile (Q3) of the Hellinger distances within each ecosystem for each proxy were calculated to use as thresholds for floristic turnover within ecosystems (Table 2). The three quartiles were also calculated for distances between ecosystems, to use as thresholds for ecosystem turnover (Table 3). These thresholds reflect different levels of confidence that turnover is taking place: Q1 is a weak indication of ecosystem turnover, Q2 is a good indication of ecosystem turnover, and Q3 is a strong indication of ecosystem turnover. Hellinger distances were calculated between all samples at all depths for pollen and phytolith data from the palaeo-record at Laguna Granja and the pollen data from Laguna Chaplin, for comparison to the thresholds identified for ecosystem turnover.

\subsection{Map}

The map of Noel Kempff Mercado National Park and surrounding ecosystems (Fig. 1) was created using ArcGIS 10.4. A vegetation classification of our study area, based on supervised Landsat imagery, was generously provided by the Museo de Historia Natural 'Noel Kempff Mercado', Santa Cruz, Bolivia in 2015.

\section{Results}

[Figure 2-Boxplots of Hellinger distances. Plot A and B show distances within individual study plots for phytoliths and pollen respectively. $\mathrm{CH}$ - terra firme evergreen liana forest, $\mathrm{LF}$ - terra firme evergreen forest, $\mathrm{AC}$ - terra firme semi-deciduous dry forest, $\mathrm{CP}$ - seasonally-inundated semideciduous dry forest, $\mathrm{MV}$ - seasonally-inundated semi-deciduous dry forest, $\mathrm{FC}$ - terra firme savannah, FT - seasonally-inundated savannah, TO - seasonally-inundated savannah. Plots C and D show distances within ecosystems, plots $\mathrm{E}$ and $\mathrm{F}$ show distances between ecosystems within biomes.]

\subsection{Variation within plots}

The level of variation between phytolith assemblages within the two plots in the evergreen forest ecosystem class $(\mathrm{CH}, \mathrm{LF})$ are similar, both in terms of median distance $(\sim 5)$ and range of distance ( $\sim 3$ 7) (Fig. 2A). Within the dry forest plots ( $A C, C P, M V$ ) the terra firme plots ( $A C$ and $C P$ ) have much higher variability than the seasonally inundated plot. In the savannah plots (FC, FT, TO) the variation between assemblages within the plots is generally lower than for the evergreen and dry forest plots.

The two evergreen plots (CH, LF) also show similar levels of variation between pollen assemblages (Fig. 2B). The dry forest plots show a different pattern however, with all three plots (AC, CP, MV), both terra firme and seasonally inundated, showing high levels of variation, although the seasonally inundated plot (MV) does show a greater range of variability than the two terra firme plots (AC, $C P$ ). The terra firme savannah plot (FC) shows particularly low variability in pollen assemblages, while the two seasonally inundated savannah plots (FT, TO) show greater variability and a greater range of variability. 


\subsection{Variation within ecosystems}

The level of variability overall is higher in the pollen assemblages than the phytolith assemblages (Fig 2C, D). For phytoliths, the dry forest ecosystem shows the highest variability and the greatest range of variability. The evergreen forest and savannah ecosystems show similar, lower levels of variability and smaller ranges (Fig. 2C). For pollen, the dry forest ecosystem also contains the highest variability in pollen assemblages, followed by evergreen forest, with savannas containing the lowest variability. The range of variability for pollen is similar across all three ecosystems (Fig. 2D).

\subsection{Variation between ecosystems}

For phytoliths, the highest variation is between evergreen forest and savannah assemblages, followed by between dry forest and savannah assemblages (Fig. 2E). The lowest variation in phytolith assemblages is between the two forested ecosystems, dry forest and evergreen forest. For pollen, all three comparisons between ecosystems show similar levels of variation between assemblages (Fig. 2F).

A one-way ANOVA (Distance Ecosystem) shows that ecosystem type is a statistically significant factor in the distribution of differences $(p=0.001)$ for both pollen and phytoliths (Tables S3 and S4). TukeysHSD post-hoc test shows that for phytoliths dry forest is significantly different to evergreen forest and savannah, but that evergreen forest and savannah are not significantly different from each other. For pollen, TukeysHSD showed that the level of variation is statistically different between all three ecosystems.

\subsection{PCA results}

[Figure 3 - Principal Component Analysis (PCA) biplots for modern and fossil samples. Panel A modern pollen samples from NKMNP plots, fossil pollen samples from Laguna Granja and Laguna Chaplin. Panel B - modern phytolith samples from NKMNP plots and fossil phytolith samples from Laguna Granja. Colours represent sample location: evergreen forest plots from NKMNP are coloured dark green; dry forest plots from NKMNP are light green; savannah plots from NKMNP are yellow; fossil samples from Laguna Chaplin are violet; fossil samples from Laguna Granja are dark blue.]

PCA results for both the modern pollen and phytoliths (Fig. 3) show differentiation of savannah (yellow), dry forest (light green) and evergreen forest (dark green) samples along PCA axis 1 with some overlap between dry and evergreen forest samples. PCA axis 1 may represent a gradient of arboreal cover, from savannah to evergreen forest. The fossil pollen samples (Fig. 3A) show differentiation of Lagunas Granja (blue) and Chaplin (violet). Laguna Chaplin samples are clustered into three time periods: the basal samples plot negatively on PCA axis 2; the intermediate samples plot towards the centre of the PCA; the most recent samples plot positively on PCA axis 1, close to the modern dry and evergreen forest samples. The fossil phytolith samples from Laguna Granja (Fig. 3B) show overlap with modern savannah and dry forest samples in the centre of the PCA.

\subsection{Thresholds for floristic and ecosystem turnover}

Table 2 - Thresholds for floristic change within ecosystems. Lower quartile, median and upper quartile of Hellinger distances between proxy assemblages within evergreen forest, dry forest and savannah from modern samples at Noel Kempff Mercado National Park (NKMNP). The lower quartile (Q1) represents a weak indication of floristic change within the ecosystem, the median (Q2) 
represents a good indication, and the upper quartile (Q3) represents a strong indication. Thresholds are given to 3 significant figures.

\begin{tabular}{|l|l|l|l|l|}
\hline Proxy & Ecosystem & $\begin{array}{l}\text { Lower } \\
\text { quartile (Q1) }\end{array}$ & Median (Q2) & $\begin{array}{l}\text { Upper } \\
\text { quartile (Q3) }\end{array}$ \\
\hline \multirow{3}{*}{ Phytolith } & Evergreen forest & 0.417 & 0.501 & 0.551 \\
\cline { 2 - 5 } & Dry forest & 0.516 & 0.821 & 0.995 \\
\cline { 2 - 5 } & Savannah & 0.313 & 0.471 & 0.540 \\
\hline \multirow{3}{*}{ Pollen } & Evergreen forest & 0.586 & 0.666 & 0.800 \\
\cline { 2 - 5 } & Dry forest & 0.698 & 0.859 & 0.967 \\
\cline { 2 - 5 } & Savannah & 0.417 & 0.528 & 0.688 \\
\hline
\end{tabular}

The range of thresholds identified for floristic turnover are the lower quartile (Q1), median (Q2) and upper quartile (Q3) of the Hellinger distances within each ecosystem, for each proxy (Table 2). These thresholds reflect the patterns of variability in the boxplots at ecosystem level (Fig. 2C, D). This pattern is generally similar for both pollen and phytoliths; the highest thresholds are in dry forest as these ecosystems presented the highest variability, while the thresholds for evergreen forest and savannah are similar and lower. The absolute values of the thresholds are slightly higher for pollen compared to phytoliths.

Table 3 - Thresholds for ecosystem turnover. Lower quartile, median and upper quartile of Hellinger distances between proxy assemblages between evergreen forest, dry forest and savannah from modern samples at Noel Kempff Mercado National Park (NKMNP). The lower quartile (Q1) represents a weak indication of ecosystem turnover, the median (Q2) represents a good indication, and the upper quartile (Q3) represents a strong indication. Thresholds are given to 3 significant figures.

\begin{tabular}{|l|l|l|l|l|}
\hline Proxy & Ecosystem & $\begin{array}{l}\text { Lower } \\
\text { quartile (Q1) }\end{array}$ & Median (Q2) & $\begin{array}{l}\text { Upper } \\
\text { quartile (Q3) }\end{array}$ \\
\hline \multirow{3}{*}{ Phytoliths } & Dry forest - evergreen forest & 0.711 & 0.820 & 0.938 \\
\cline { 2 - 5 } & Dry forest - savannah & 0.843 & 0.962 & 1.06 \\
\cline { 2 - 5 } & Evergreen forest - savannah & 0.986 & 1.15 & 1.22 \\
\hline \multirow{3}{*}{ Pollen } & Dry forest - evergreen forest & 0.784 & 0.873 & 0.967 \\
\cline { 2 - 5 } & Dry forest - savannah & 0.779 & 0.892 & 0.975 \\
\cline { 2 - 5 } & Evergreen forest - savannah & 0.781 & 0.835 & 0.898 \\
\hline
\end{tabular}

The ecosystem turnover thresholds are the lower (Q1), median (Q2) and upper quartiles (Q3) for between ecosystem distances (Table 3). The highest thresholds for phytoliths are for turnover between evergreen forest and savannah, followed by dry forest and savannah. Turnover between the two forested ecosystems has the lowest threshold. For pollen, the threshold is similar for turnover between all three ecosystems. 


\subsubsection{Application of thresholds to L. Granja}

The original interpretation of the pollen and phytolith records (Carson et al., 2015) were used to identify the direction of change between ecosystems and select the appropriate thresholds to apply to pairwise comparisons of the pollen and phytoliths records down-core at L. Granja and Chaplin.

[Figure 4 - Stratigraphic plots of Hellinger distances between pairwise assemblages downcore at Laguna Granja (phytoliths and pollen) and Laguna Chaplin (pollen). Age-depth models taken from original papers (Burbridge et al., 2004; Carson et al., 2015). Red dashed lines represent thresholds for floristic change within the ecosystem: lower quartile (Q1), median (Q2) and upper quartile (Q3) of Hellinger distances for the appropriate ecosystem and proxy, calculated based on modern distances between samples in vegetation study plots at Noel Kempff Mercado National Park (NKMNP) (Table 2). For Granja phytoliths, the thresholds for evergreen forest are plotted. For Granja and Chaplin pollen, the thresholds for savannah are plotted. Green dashed lines represent thresholds for ecosystem turnover: lower quartile (Q1), median (Q2) and upper quartile (Q3) of Hellinger distances for the turnover between evergreen forest and savannah, for the appropriate proxy (Table 3).]

Carson et al., (2015) interpret the phytolith record at L. Granja to represent local riparian gallery forest around the edges of the lake from $6,000-2,500 \mathrm{yBP}$, followed by an opening up of the forest from 2,500-500 yBP, and then expansion of the gallery forest within the last 500 years (Fig. S5). Therefore, the phytolith thresholds for evergreen forest (Table 2) were selected to compare to the pairwise distances down-core in the phytolith record. The three basal phytolith pairwise distances meet or exceed the Q3 threshold indicating strong evidence of floristic turnover within the ecosystem (Fig. 4). Throughout the middle of the core, pairwise distances meet the Q1 threshold indicating weak evidence for floristic turnover within the ecosystem. In the top section of the core, pairwise distances fluctuate below the Q1 threshold, only reaching the Q1 threshold three further times (Fig. 4). The thresholds for ecosystem turnover (Table 3) are not met throughout the core.

Carson et al., (2015) interpret the pollen record at L. Granja to represent open, terra firme savannah from $6,000 \mathrm{yBP}$ to $500 \mathrm{yBP}$ when terra firme evergreen forest expands into the surrounding landscape (Fig. S6). Therefore, the pollen thresholds for savannah (Table 2) were selected to compare to the pairwise distances down-core in the pollen record. Almost all pairwise distances from the pollen record fluctuate between the Q1 and Q3 thresholds for floristic turnover (Fig. 4). From 6,000 calyrBP to 2,500 calyrBP most distances meet the Q2 threshold, indicating good evidence for floristic turnover. From 2,500 calyrBP to 1,500 calyrBP distances are closer to the Q1 threshold for weak indication of floristic turnover. From 1,500 calyrBP to present, distances are close to the Q2 threshold, showing good evidence of floristic turnover. The thresholds for ecosystem turnover (Table 3) are not met throughout the core.

In addition to pairwise distances down-core, the distances between all samples at all depths were also calculated. To test whether the high levels of variation between the basal three phytolith samples at L. Granja was due to the low sampling resolution (500 years c.f. $<100$ years near the top of the core), the thresholds for floristic and ecosystem turnover were compared to distances between all samples. In the phytolith record from L. Granja, Q1 threshold for weak indication of floristic turnover is met by comparison of the top section from 600 calyrBP to present with the rest of the core, matching the timing of gallery forest expansion interpreted by Carson et al., (2015). The 
Q2 and Q3 thresholds for good and strong indication of floristic turnover are only met by the three basal samples identified by pairwise comparison downcore. The three thresholds for ecosystem turnover are only met by isolated comparisons of specific samples. In the pollen record from $\mathrm{L}$. Granja, the Q2 threshold for good indication of floristic turnover is met by comparison of the top section from 500 calyrBP to present with the rest of the core, matching the timing of ecosystem turnover from savannah to evergreen forest identified by Carson et al., (2015). The Q3 threshold for floristic turnover and all three thresholds for ecosystem turnover are only met by isolated comparisons of specific samples.

\subsubsection{Application of thresholds to L. Chaplin}

Mayle et al., (2000) and Burbridge et al., (2004) interpret the pollen record at L. Chaplin to represent a palm savannah marsh from 51,000 to 48,000 yBP, then a seasonally inundated savannah with areas of semi-deciduous dry forest from $\sim 48,000$ to $2000 \mathrm{yBP}$, after which ecosystem turnover occurred and humid evergreen forest expanded to dominate the lake catchment (Fig. S7). Therefore, the pollen thresholds for savannah (Table 2) were selected to compare to the pairwise distances down-core. The majority of pairwise distances are close to the Q1 threshold, indicating weak evidence for floristic turnover (Fig. 4). One distance meets the Q2 threshold, indicating good evidence for floristic turnover, at 48,000 calyrBP coincident with the change from palm savannah marsh to seasonally inundated savannah (Burbridge et al., 2004). The ecosystem turnover identified by the authors at 2,000 calyrBP does not meet the Q2 or Q3 thresholds for floristic change. The thresholds for ecosystem turnover are not met throughout the core (Fig. 4).

However, when comparing the full matrix of sample depths, the Q3 threshold for strong indication of floristic turnover is reached by comparisons between the top section of the core $(2,500$ calyrBP to present) with the majority of the rest of core. Furthermore, the Q2 threshold for good indication of ecosystem turnover is met by comparisons between the top 3,000 calyrBP to present section with the majority of the rest of the core. This broadly matches the interpretation of (Burbridge et al., 2004; Mayle et al., 2000) that ecosystem turnover occurred around 2,000 calyrBP from a savannahforest community to an evergreen forest community.

\section{Discussion}

\subsection{Variability in pollen and phytolith assemblages}

The overall magnitude of variability is higher in the pollen assemblages than the phytolith assemblages (Fig 2C, D). This reflects the higher diversity of pollen types within tropical ecosystems, which can be $>100$ from one site, compared to phytolith types which do not normally exceed 50 .

At the plot level, particularly high levels of variability were found within both humid evergreen forest plots and individual semi-deciduous dry forest plots (Fig. 2A, B). The high variability within these 1hectare plots has implications for small-scale palaeo-ecological studies such as from soil pits or peat cores, as it shows that a significant amount of variability in the phytolith or pollen assemblage is consistent with samples from within one modern plant community. Caution is therefore required in interpretation of floristic changes at the scale of a single soil pit or peat core, as small changes in the pollen or phytolith records may only reflect proxy variability within that ecosystem. For example, increases in phytolith palm abundance within evergreen forest soil pit samples has been interpreted as a record of human influence in Acre state, Brazil (Watling et al., 2017) but this may instead reflect the high variability in phytolith assemblages from evergreen forest soil samples. The down-profile 
variation seen in the soil phytolith palaeo-record may therefore not reflect significant floristic changes in the vegetation. This demonstrates the importance of using a modern training dataset to define the level of variation in modern assemblages from within a plant community to enable the differentiation of proxy noise from significant vegetation change.

At the ecosystem level, the highest variability in both pollen and phytolith assemblages was found in dry forest (Fig 2C, D). This is likely to be partly due to the differences between the two dry forest types included in this classification. The dry forest ecosystem class contains both seasonally inundated and terra firme dry forest, which the vegetation inventories show to be floristically distinct in terms of the most dominant tree species (SALVIAS, 2004). For example, in the terra firme plots, the most common taxa are Caesalpinia floribunda, Tabebuia roseo-alba, and Anadenanthera colubrina whereas in the seasonally inundated plots the most common taxa are Inga ingoides, Physocalymma scaberimum and Hirtella gracilipes (Dickau et al., 2013). This floristic difference in tree species explains the different levels of variation in the pollen assemblage between the two types of dry forest. The more significant difference between the two forest types in the phytolith assemblages (Fig. 2A) suggests that there is more significant variation in the understorey vegetation of these forests, as phytoliths are well suited for differentiation of herbaceous taxa (Piperno, 2006). Given the variation in inundation regime, variation in understorey vegetation would be expected. Unfortunately, the vegetation inventories for forest plots did not sample herbaceous taxa so this cannot be empirically tested. However, these results suggest that phytoliths may be more sensitive to the variability between different dry forest types, due to their ability to detect variability in the understorey vegetation. Therefore, to detect changes in inundation regime within dry forest ecosystems, phytoliths may be a better proxy choice than pollen.

Within evergreen forest, pollen assemblages show higher variability than phytolith assemblages (Fig 2C, D). This likely reflects the ability of pollen to differentiate a wide range of arboreal taxa common to these plant communities, such as Moraceae, Alchornea and Melastomataceae/Combretaceae. As phytoliths generally only produce general arboreal indicators, such as granulate globulars, they are not able to pick up the spatial variability in tree species within these plots. In contrast to the dry forest, evergreen forests tend to have dense canopies leading to less well-developed understorey vegetation (Killeen and Schulenberg, 1998). Therefore, there is scarce herbaceous variability for the phytolith record to record within evergreen forest. These results show that pollen is more sensitive to variability within evergreen forest than phytoliths, due to their ability to detect changes in arboreal floristic composition.

Within the savannah communities, pollen and phytolith assemblages show similar levels of variability (Fig $2 \mathrm{C}, \mathrm{D}$ ), although phytoliths are more sensitive to variation in terra firme upland savannah, and pollen more sensitive to variation in seasonally-inundated savannah (Fig. 2A, B). This reflects the complex mixture of both arboreal and herbaceous vegetation which forms the majority of savannah plant communities in south-west Amazonia. Cerrado savannah physiognomies range from closed woodland (cerradão) to open grassland with no trees or shrubs (campo limpo) (Oliveira Filho and Ratter, 2002). The cerrado savannah plot here represents open woodland savannah (campo cerrado) (Jones et al., 2011). Within seasonally inundated savannahs, low-elevation areas are almost entirely dominated by grasses, while trees and shrubs are found on raised islands, particularly termite mounds (pampa termitero) in NKMNP (Killeen and Schulenberg, 1998). Pollen may therefore be capturing the variability in savannah trees, both in upland cerrado formations and 
on islands within seasonally inundated savannah but does not provide the taxonomic resolution to capture variability in grass genera and subfamilies. In contrast, phytoliths will capture the variability in the grasses and herbaceous taxa but not in the majority of the arboreal taxa (Piperno, 2006). Phytoliths may therefore be well suited to detecting local changes such as the inundation regime in savannas while pollen may be a better choice of proxy for detection of regional climatic changes such as reductions in precipitation (Carson et al., 2015; Piperno, 2006; Whitney et al., 2013).. However, to fully investigate savannah dynamics both pollen and phytoliths should be used together to provide taxonomic detail on both the herbaceous and arboreal components of the ecosystem (Dickau et al., 2013).

\subsection{Modern analogues for fossil samples}

The overlap between the modern and fossil phytolith samples in the PCA (Fig 3B) suggests the modern samples represent good analogues for fossil assemblages, and supports the use of thresholds based on the modern phytolith samples to infer ecosystem turnover in the fossil record. The overlap for modern and fossil pollen samples is less strong (Fig 3A). The modern pollen samples do show good overlap in ordination space with the most recent $(2,500$ calyrBP to present) fossil samples from Laguna Chaplin, but less overlap with the older Chaplin samples or the Laguna Granja fossil samples. L. Granja is situated $250 \mathrm{~km}$ to the north west of NKMNP and L. Chaplin (Fig. 1). L. Granja is situated at the ecotone between humid evergreen forest to the north and the Beni seasonally-inundated savannah- forest mosaic to the south (Fig. 1). The savannah of the Beni basin has a distinct vegetation composition whose pollen rain differs from seasonally-inundated savannah communities in NKMNP: Beni basin pollen rain contains a higher proportion of Poaceae and Cyperaceae and lower Moraceae/Urticaceae than NKMNP pollen rain (Jones et al., 2011). The lack of ordination overlap between L. Granja pollen and modern NKMNP pollen suggests that modern samples specific to the local vegetation of a study site should be used where possible to develop thresholds for floristic and ecosystem turnover, particularly for pollen due to the high diversity of pollen types. For phytoliths, the need for local samples may be less important as there is a lower diversity of phytolith types.

\subsection{Thresholds for floristic and ecosystem turnover in the palaeo-record}

The pollen Q1 threshold for weak indication of floristic turnover within savannah was met several times through the pairwise downcore comparisons at L. Chaplin (Fig. 4). However, the pairwise distances downcore do not meet the thresholds for stronger floristic turnover or ecosystem turnover at 2,000 calyrBP, the time at which Burbridge et al., (2004) interpret turnover from savannah and dry forest to evergreen forest. This may reflect the fact that the vegetation changes are gradual transitions that are not captured in a single pairwise distance measure. When the full matrix of distances between all samples at all depths was compared, the Q2 threshold for good indication of ecosystem turnover was met by comparison of the top section from 3,000 calyrBP to present with the majority of the rest of the core. This is close to the timing of the ecosystem turnover identified by qualitative interpretation of the pollen record.

At L. Granja, the pollen Q2 threshold for good indication of floristic turnover was met by the majority of the pairwise comparisons downcore, indicating evidence of floristic turnover within the savannah ecosystem throughout the majority of the record (Fig. 4). However, the pairwise distances downcore do not meet the thresholds for strong (Q3) floristic or ecosystem turnover at 500 calyrBP when Carson et al., (2015) identify ecosystem turnover from savannah to evergreen forest. When the full 
matrix of distances between all samples at all depths was compared, the Q2 threshold for good indication of floristic turnover within savannah was met by comparison of the last 500 years to present with the rest of the core, which matches the timing of the transition identified from qualitative interpretation of the pollen record. However, the transition at 500 calyrBP did not meet any of the thresholds for ecosystem turnover from savannah to evergreen forest. This may be due to the spatial scale of the change within the catchment of the lake. At present L. Granja is at the very edge of the Amazonian evergreen forest, at the boundary with seasonally-inundated savannah of the Beni basin. Therefore, within the catchment of L. Granja, there would not have been a complete transition from savannah to evergreen forest as the Beni is hydrologically controlled and would have remained savanna-dominated throughout. In comparison, at present L. Chaplin is surrounded almost entirely by evergreen forest, so the transition in the catchment of the lake would have been more significant. These findings demonstrate the importance of considering the local characteristics of the site and heterogeneity of the surrounding landscape in interpretation of the thresholds. Both the spatial and temporal elements of the vegetation change are captured by these thresholds.

In the phytolith record at L. Granja, the Q3 threshold for strong indication of floristic turnover was met at the base of the core, not at the depths identified for vegetation change by the authors (Carson et al., 2015). The phytolith record at the depths where the Q3 floristic turnover threshold was reached shows high abundance of Asteraceae phytoliths in particular. This single taxon appears to be driving the large differences between these samples and the rest of the core. This highlights the importance of considering the taxonomic detail of the changes in the record alongside the level of variation in assemblage to identify ecosystem turnover; not all taxa are weighted equally in the qualitative interpretation of palaeo-records. However, when all samples at all depths are compared, the top section of the core from 600 calyrBP to present meets the Q1 threshold for weak indication of floristic turnover compared to the rest of the core. This fits the timing of the closing of the forest canopy around the lake edge identified by (Carson et al., 2015). The lower threshold for floristic change (Q1) is therefore capturing the small scale of vegetation change reflected in the phytolith record.

These findings demonstrate the importance of this quantitative approach for assessing the magnitude of vegetation change in the palaeo-record. Use of these thresholds enables differentiation between the magnitude of variation that represents floristic turnover within an ecosystem from that which represents turnover between ecosystems. At L. Chaplin, the vegetation changes between 3,000 and 2,000 calyrBP are of high enough magnitude to be identified as a good indication of ecosystem turnover. However, the changes in the pollen record at L. Granja at 500 calyrBP are only high enough to be identified as a good indication of floristic turnover within an ecosystem. The changes in the phytolith record at L. Granja at 600 calyrBP only represent a weak indication of floristic turnover within an ecosystem. These thresholds therefore provide quantitative distinctions between different scales of turnover in the palaeo-record and enable differentiation of ecosystem turnover from floristic turnover within the ecosystem.

However, it is important to consider that these thresholds were only able to capture floristic turnover or ecosystem turnover by comparison of the full matrix of distances between all samples at all depths. Pairwise downcore distances mostly did not meet the thresholds for floristic or ecosystem turnover at the depths that qualitative interpretation of the records suggested turnover was taking place. This may reflect the gradual nature of these vegetation transitions. Previous research has 
demonstrated that lowland south-western Amazonian sites, such as L. Chaplin, have low rates of ecological change (Costa et al., 2018). Therefore sampling resolution and sedimentation rate will strongly influence the magnitude of change captured by single pairwise distances downcore. Sampling resolution and sedimentation rate can be accounted for by calculating the rate of ecological change for fossil samples (Urrego et al., 2009) but this is not possible for modern samples. As the methodology of this paper relies on comparison of modern proxy variability to fossil proxy variability, sampling resolution and sedimentation rate needs to be accounted for by comparison of the full matrix of distances between all samples at all depths in the palaeo-record.

Future development of this quantitative methodology for identifying ecosystem turnover in the palaeo-record relies on development and expansion of modern training datasets of pollen and phytolith variability to set thresholds. The NKMNP dataset used in this study is currently the only dataset in tropical South America with both pollen and phytolith data from permanent vegetation study plots within evergreen forest, dry forest and savannah. One outstanding question is whether the thresholds calculated from the NKMNP data are applicable to palaeo-records from other parts of south-western Amazonia. Despite the lack of overlap in ordination space between the modern pollen samples from NKMNP and the fossil samples from L. Granja (Fig. 3A), the thresholds were still able to capture the vegetation turnover at 500 calyrBP in the palaeo-record. Applicability of these thresholds could be further tested through study of palaeo-sites from outside NKMNP.

Applying these thresholds to additional sites where ecosystem turnover has been interpreted from the fossil record would also enable a sensitivity analysis of the threshold levels used here. In this pilot investigation, thresholds we set based on the $25^{\text {th }}, 50^{\text {th }}$ and $75^{\text {th }}$ percentile of variation in the modern datasets. These threshold levels could be refined through testing on additional palaeo-sites. Applying this approach to numerous palaeo-sites may also improve our understanding of whether different drivers of floristic or ecosystem turnover produce different levels of variability in taxonomic composition. For example, does fire-induced vegetation change produce the same amount of taxonomic variability as flood-induced vegetation change or human-induced vegetation change? The high variability in rates of ecological change found in palaeo-records across tropical South America in the last 3,000 years has been linked to human-induced vegetation change (Urrego et al., 2009). Patterns of variability in the palaeo-record may therefore help distinguish between climate-induced vegetation change, which may show more gradual variation, and human-induced vegetation change.

\section{Conclusions}

This research aimed to compare the sensitivity of pollen and phytolith assemblages to changes within and between three tropical South American ecosystems: evergreen forest, dry forest and savannah. Pollen is more sensitive than phytoliths to variation in evergreen forest due to pollen's superior ability to differentiate arboreal taxa which dominate this forest type. Phytoliths are slightly more sensitive than pollen to variation in dry forest due to their greater ability to capture changes in understorey herbaceous taxa associated with differences in canopy density. Phytoliths may be particularly sensitive to changes in inundation regime in dry forests. Both pollen and phytoliths are equally sensitive to variation in savannas due to the complex mixture of arboreal and herbaceous taxa in these communities. Phytoliths may be best suited to investigate changes in inundation regime affecting herbs and grasses in low-elevation areas, while pollen may be best suited to investigate climatic changes affecting arboreal composition within savannas. These findings support the suggestion that the two proxies provide different, complementary taxonomic information and 
should be used together to improve our understanding of these complex ecosystem dynamics (Dickau et al., 2013; Plumpton et al., submitted). Overall, this analysis shows that the relative sensitivity of the two proxies to changes within an ecosystem depends on the ecosystem type studied. These are important considerations for palaeoecologists selecting proxies for the study of ecosystem turnover in the palaeo-record.

This research also aimed to use the variability in the proxy assemblages from evergreen forest, dry forest and savannah as a modern training dataset to define thresholds which could distinguish floristic change within an ecosystem from turnover between ecosystems. When applied to palaeorecords from two test sites, the thresholds reflected the changes identified by the authors of the records and largely differentiated ecosystem turnover from floristic turnover. The thresholds have been shown to provide quantitative distinctions between different scales of turnover in the palaeorecord. These results demonstrate the potential of this quantitative approach for assessing the magnitude of vegetation change in the palaeo-record and differentiating ecosystem turnover from floristic changes within an ecosystem. This quantitative approach is therefore a useful tool for palaeoecologists to apply alongside qualitative interpretation of the palaeo-record for identification of ecosystem turnover.

\section{Acknowledgements}

Funding for the analysis in this paper was provided by a University of Reading PhD studentship (HP). We thank William Gosling, Michael Burn, Huw Jones and Ruth Dickau for permission to use their pollen and phytolith data from Noel Kempff Mercado National Park, and John Carson and Jenny Watling for permission to use their pollen and phytolith data from Laguna Granja. We also thank the reviewers for their useful comments and suggestions which helped to improve this manuscript.

\section{References}

Burbridge RE, Mayle FE and Killeen TJ (2004) Fifty-thousand-year vegetation and climate history of Noel Kempff Mercado National Park, Bolivian Amazon. Quaternary Research 61(2): 215-230. DOI: 10.1016/j.yqres.2003.12.004.

Burn MJ, Mayle FE and Killeen TJ (2010) Pollen-based differentiation of Amazonian rainforest communities and implications for lowland palaeoecology in tropical South America. Palaeogeography, Palaeoclimatology, Palaeoecology 295(1-2): 1-18. DOI: 10.1016/j.palaeo.2010.05.009.

Bush MB, Silman MR and Urrego DH (2004) 48,000 years of Climate and Forest Change in a Biodiversity Hot Spot.

Carson JF, Watling J, Mayle FE, et al. (2015) Pre-Columbian land use in the ring-ditch region of the Bolivian Amazon. The Holocene 25(8): 1285-1300. DOI: 10.1177/0959683615581204.

Colinvaux PA, de Oliveira PE and Patiño JEM (1999) Amazon Pollen Manual and Atlas. Amsterdam: Harwood Academic Publishers.

Costa GC, Hampe A, Ledru M-P, et al. (2018) Biome stability in South America over the last 30 kyr: Inferences from long-term vegetation dynamics and habitat modelling. Global Ecology and Biogeography 27(3). John Wiley \& Sons, Ltd (10.1111): 285-297. DOI: 10.1111/geb.12694.

Dickau R, Whitney BS, Iriarte J, et al. (2013) Differentiation of neotropical ecosystems by modern soil phytolith assemblages and its implications for palaeoenvironmental and archaeological 
reconstructions. Review of Palaeobotany and Palynology 193. Elsevier B.V.: 15-37. DOI: 10.1016/j.revpalbo.2013.01.004.

Dowsett H, Dolan A, Rowley D, et al. (2016) The PRISM4 (mid-Piacenzian) paleoenvironmental reconstruction. Climate of the Past 12(7): 1519-1538. DOI: 10.5194/cp-12-1519-2016.

Gosling WD, Mayle FE, Tate NJ, et al. (2005) Modern pollen-rain characteristics of tall terra firme moist evergreen forest, southern Amazonia. Quaternary Research 64(3). Late Quaternary Tropical Ecosystem Dynamics: 284-297. DOI: 10.1016/j.yqres.2005.08.008.

Gosling WD, Mayle FE, Tate NJ, et al. (2009) Differentiation between Neotropical rainforest, dry forest, and savannah ecosystems by their modern pollen spectra and implications for the fossil pollen record. Review of Palaeobotany and Palynology 153(1-2): 70-85. DOI: 10.1016/j.revpalbo.2008.06.007.

Grimm EC and Jacobson GL (1992) Fossil-pollen evidence for abrupt climate changes during the past 18000 years in eastern North America. Climate Dynamics 6(3-4). Springer-Verlag: 179-184. DOI: 10.1007/BF00193530.

Holling CS (1973) Resilience and Stability of Ecological Systems. Annual Review of Ecology and Systematics 4(1). Annual Reviews 4139 El Camino Way, P.O. Box 10139, Palo Alto, CA 943030139, USA : 1-23. DOI: 10.1146/annurev.es.04.110173.000245.

Jones HT (2009) Characterisation of neotropical savanna and seasonally dry forest ecosystems by their modern pollen rain. The University of Edinburgh. Available at: https://www.era.lib.ed.ac.uk/handle/1842/4257 (accessed 26 October 2018).

Jones HT, Mayle FE, Pennington RT, et al. (2011) Characterisation of Bolivian savanna ecosystems by their modern pollen rain and implications for fossil pollen records. Review of Palaeobotany and Palynology 164(3-4): 223-237. DOI: 10.1016/j.revpalbo.2011.01.001.

Killeen TJ and Schulenberg TS (1998) A Biological Assessment of Parc Nacional Noel Kempff Mercado, Bolivia, RAP Working Papers 10. Washington, DC: Conservation International.

Legendre P and Birks HJB (2012) Chapter 8: From Classical to Canonical Ordination. In: Birks HJB, Lotter AF, Juggins S, et al. (eds) Tracking Environmental Change Using Lakes Sediment: Volume 5 Data Handling and Numerical Techniques. Springer, pp. 201-248. DOI: 10.1007/978-94-0072745-8.

Legendre P and Gallagher ED (2001) Ecologically meaningful transformations for ordination of species data. Oecologia 129(2). Springer Berlin Heidelberg: 271-280. DOI: $10.1007 / \mathrm{s} 004420100716$.

Mace GM, Reyers B, Alkemade R, et al. (2014) Approaches to defining a planetary boundary for biodiversity. Global Environmental Change 28. Pergamon: 289-297. DOI: 10.1016/J.GLOENVCHA.2014.07.009.

Malhi Y, Phillips OL, Llloyd J, et al. (2002) An international network to monitor the structure, composition and dynamics of Amazonian forests (RAINFOR). Journal of Vegetation Science 13(3): 439-450. Available at: http://www.rainfor.org/upload/publication-store/itm_81/Malhi Y et al JVS 2002.pdf (accessed 1 June 2015).

Mayle FE, Burbridge R and Killeen TJ (2000) Millennial-scale dynamics of southern Amazonian rain forests. Science (New York, N.Y.) 290(2000): 2291-2294. DOI: 10.1126/science.290.5500.2291. 
Oliveira Filho AT and Ratter JA (2002) Vegetation physiognomies and woody flora of the cerrado biome. In: The Cerrados of Brazil. Ecology an Natural History of a Neotropical Savanna (P.S. Oliveira \& R.J. Marquis, Eds.). Columbia University Press, New York., pp. 91-120.

Overpeck JT, Webb T and Prentice IC (1985) Quantitative Interpretation of Fossil Pollen Spectra: Dissimilarity Coefficients and the Method of Modern Analogs. Quaternary Research 23(01). Cambridge University Press: 87-108. DOI: 10.1016/0033-5894(85)90074-2.

Piperno DR (2006) Phytoliths: A Comprehensive Guide for Archeologists and Paleoecologists. Altamire Press.

Rockström J, Steffen W, Noone K, et al. (2009) A safe operating space for humanity. Nature 461(7263): 472-475. DOI: 10.1038/461472a.

Roubik D and Moreno P (1991) Pollen and spores of Barro Colorado Island. Monographs in systematic botany, Missouri Botanical Garden, St. Louis 36.

SALVIAS (2004) SALVIAS: Synthesis and Analysis of Local Vegetation Inventories Across Scales. Available at: http://www.salvias.net (accessed 25 October 2018).

Scheffer M, Bascompte J, Brock WA, et al. (2009) Early-warning signals for critical transitions. Nature 461(7260). Nature Publishing Group: 53-59. DOI: 10.1038/nature08227.

Seddon AW, Macias-Fauria M and Willis KJ (2015) Climate and abrupt vegetation change in Northern Europe since the last deglaciation. The Holocene 25(1). SAGE PublicationsSage UK: London, England: 25-36. DOI: 10.1177/0959683614556383.

Seddon AWR, Mackay AW, Baker AG, et al. (2014) Looking forward through the past: identification of 50 priority research questions in palaeoecology. McGlone M (ed.) Journal of Ecology 102(1): 256-267. DOI: 10.1111/1365-2745.12195.

Shuman B, Bartlein PJ and Webb T (2005) The magnitudes of millennial- and orbital-scale climatic change in eastern North America during the Late Quaternary. Quaternary Science Reviews 24(20-21). Pergamon: 2194-2206. DOI: 10.1016/J.QUASCIREV.2005.03.018.

Shuman BN and Newby P (2009) Abrupt climate change as an important agent of ecological change in the Northeast U.S. throughout the past 15,000 years. Quaternary Science Reviews 28(17-18). Pergamon: 1693-1709. DOI: 10.1016/J.QUASCIREV.2009.04.005.

Urrego DH, Bush MB, Silman MR, et al. (2009) Millennial-Scale Ecological Changes in Tropical South America Since the Last Glacial Maximum. In: Past Climate Variability in South America and Surrounding Regions, pp. 283-300. DOI: 10.1007/978-90-481-2672-9_12.

Watling J, Iriarte J, Whitney BS, et al. (2016) Differentiation of neotropical ecosystems by modern soil phytolith assemblages and its implications for palaeoenvironmental and archaeological reconstructions II: Southwestern Amazonian forests. Review of Palaeobotany and Palynology 226: 30-43. Available at: https://www.sciencedirect.com/science/article/pii/S0034666715002262.

Watling J, Iriarte J, Mayle FE, et al. (2017) Impact of pre-Columbian 'geoglyph' builders on Amazonian forests. Proceedings of the National Academy of Sciences of the United States of America 114(8). National Academy of Sciences: 1868-1873. DOI: 10.1073/pnas.1614359114.

Whitney BS, Dickau R, Mayle FE, et al. (2013) Pre-Columbian landscape impact and agriculture in the Monumental Mound region of the Llanos de Moxos, lowland Bolivia. Quaternary Research 
80(2): 207-217. DOI: 10.1016/j.yqres.2013.06.005.

List of Figures

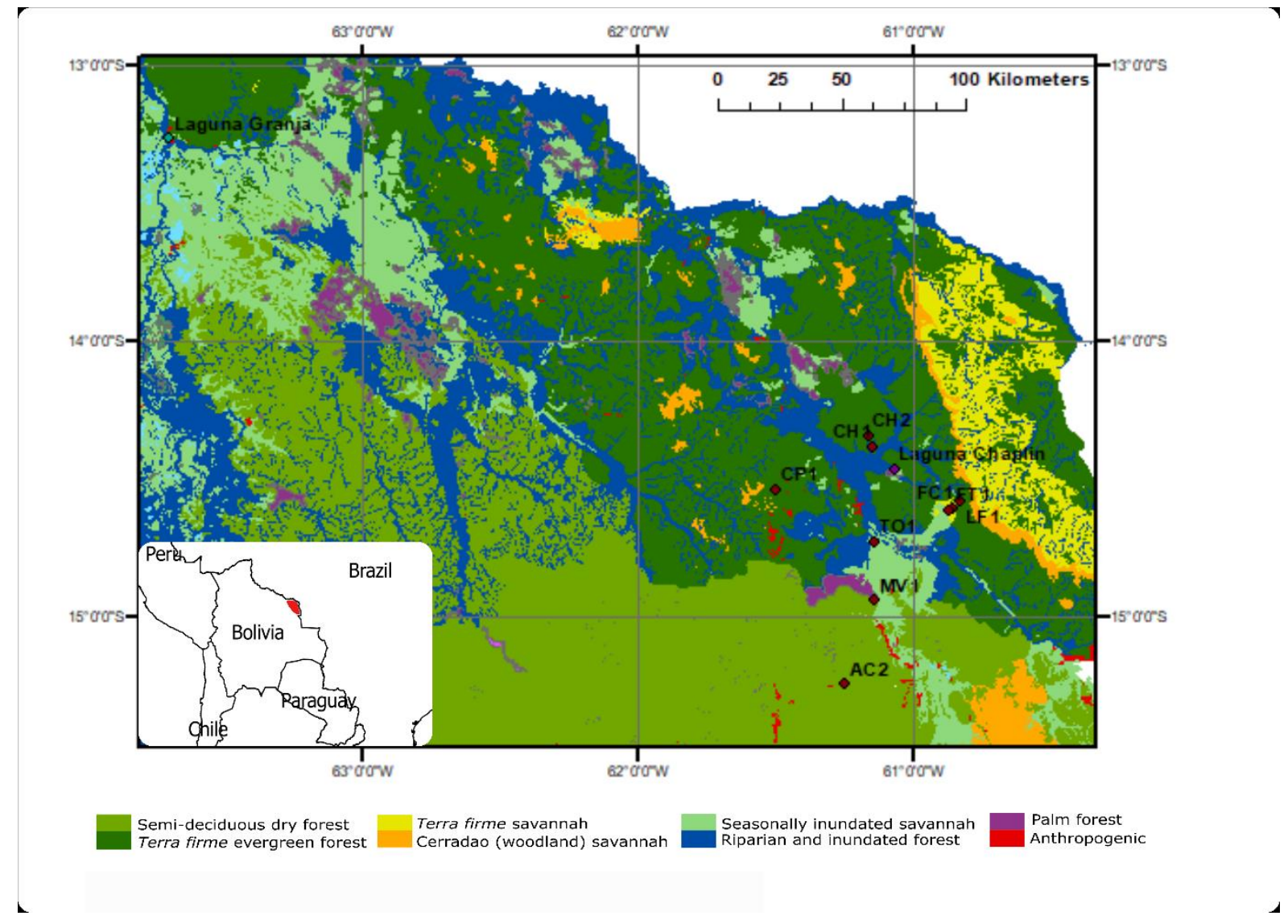

Figure 1 - Map of Noel Kempff Mercado National Park (NKMNP) showing major vegetation communities and location of plots MV1, AC2, CP1, LF1, CH1, CH2, FC1, TO1, FT1, and Lagunas Granja and Chaplin. Inset map of South American countries with red-shaded area showing location of NKMNP. 
Phytoliths
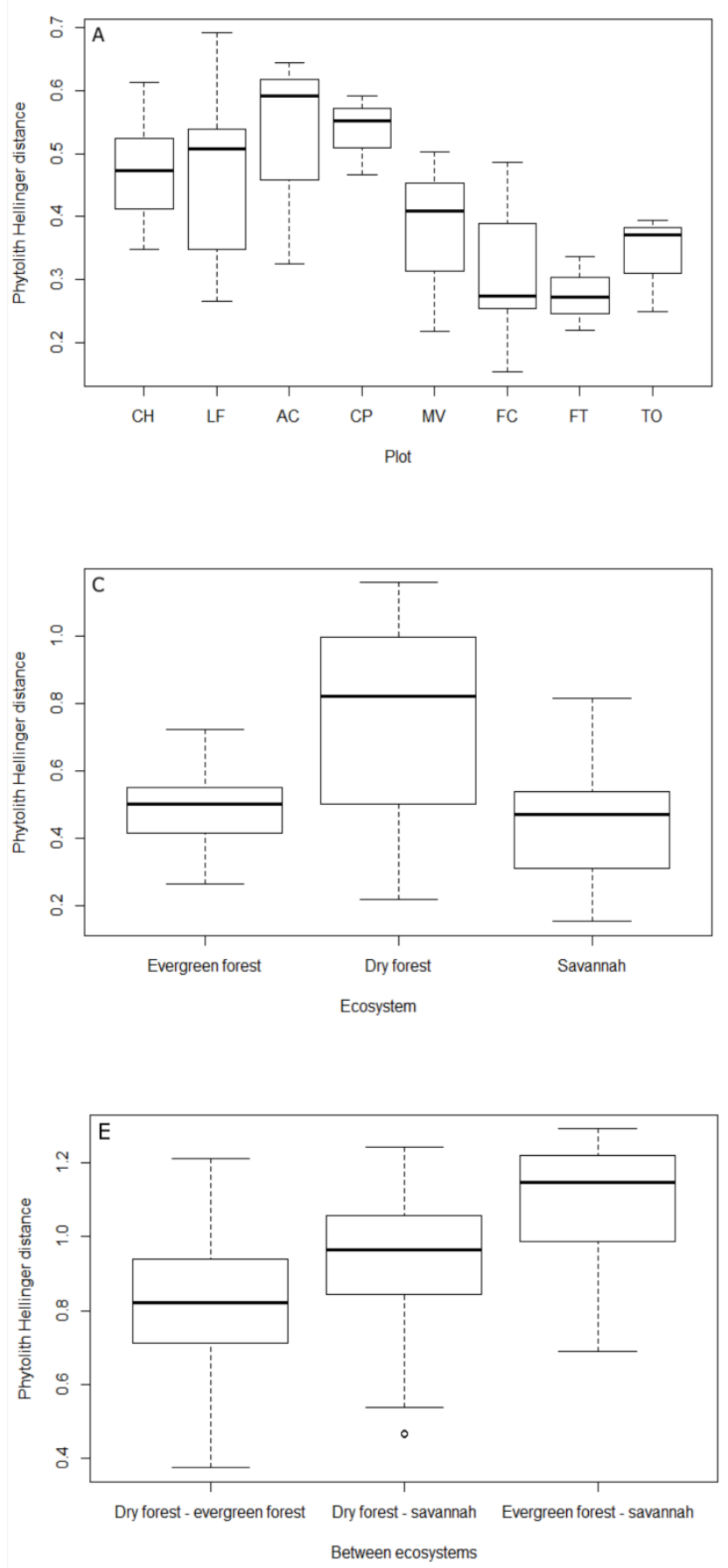

Pollen
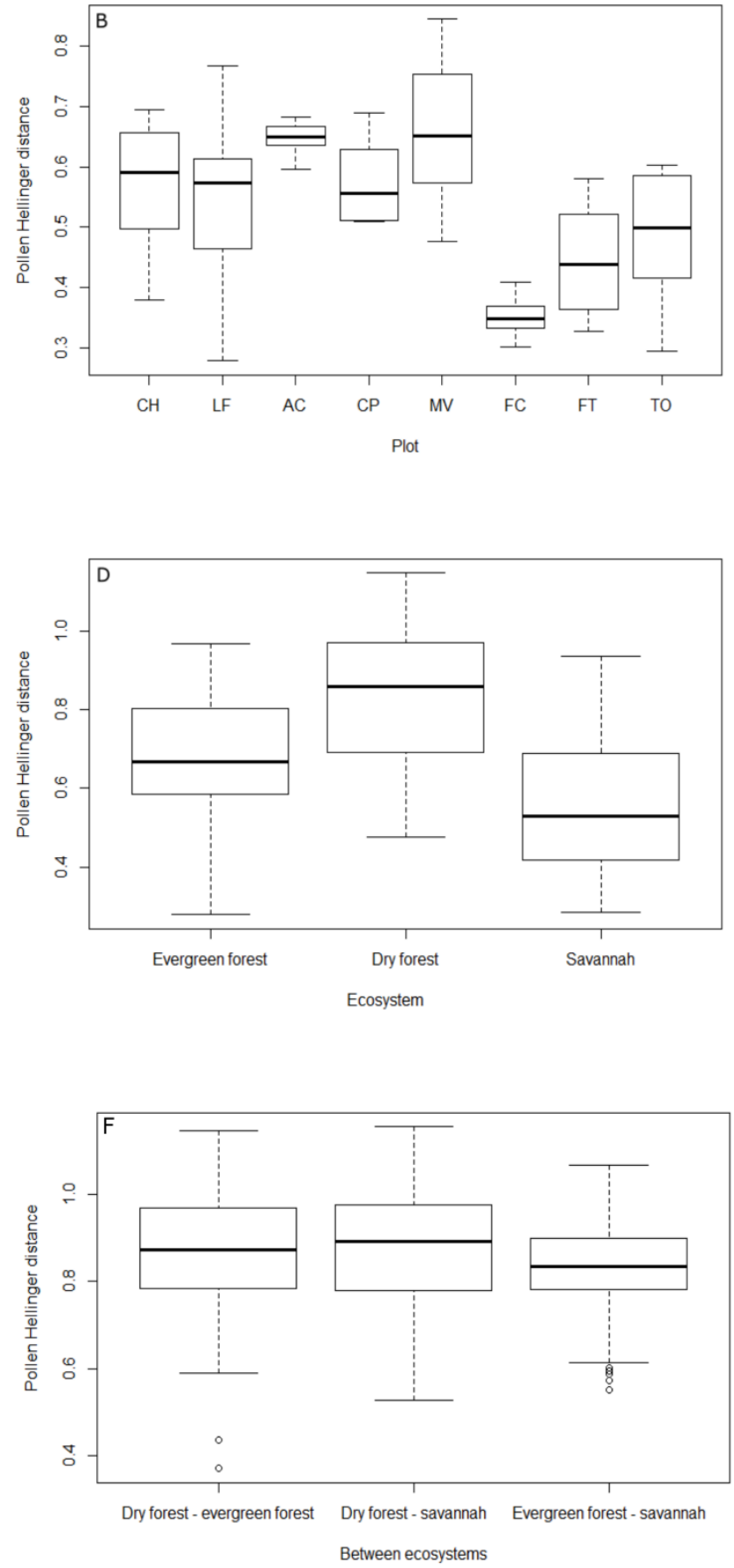

Figure 2 - Boxplots of Hellinger distances. Plot $A$ and $B$ show distances within individual study plots for phytoliths and pollen respectively. $\mathrm{CH}$ - terra firme evergreen liana forest, $\mathrm{LF}$ - terra firme evergreen forest, $\mathrm{AC}$ - terra firme semi-deciduous dry forest, $\mathrm{CP}$ - seasonally-inundated semideciduous dry forest, $\mathrm{MV}$ - seasonally-inundated semi-deciduous dry forest, $\mathrm{FC}$ - terra firme savannah, FT - seasonally-inundated savannah, TO - seasonally-inundated savannah. Plots C and D show distances within ecosystem classes, plots $\mathrm{E}$ and $\mathrm{F}$ show distances between ecosystem classes within biomes. 
A
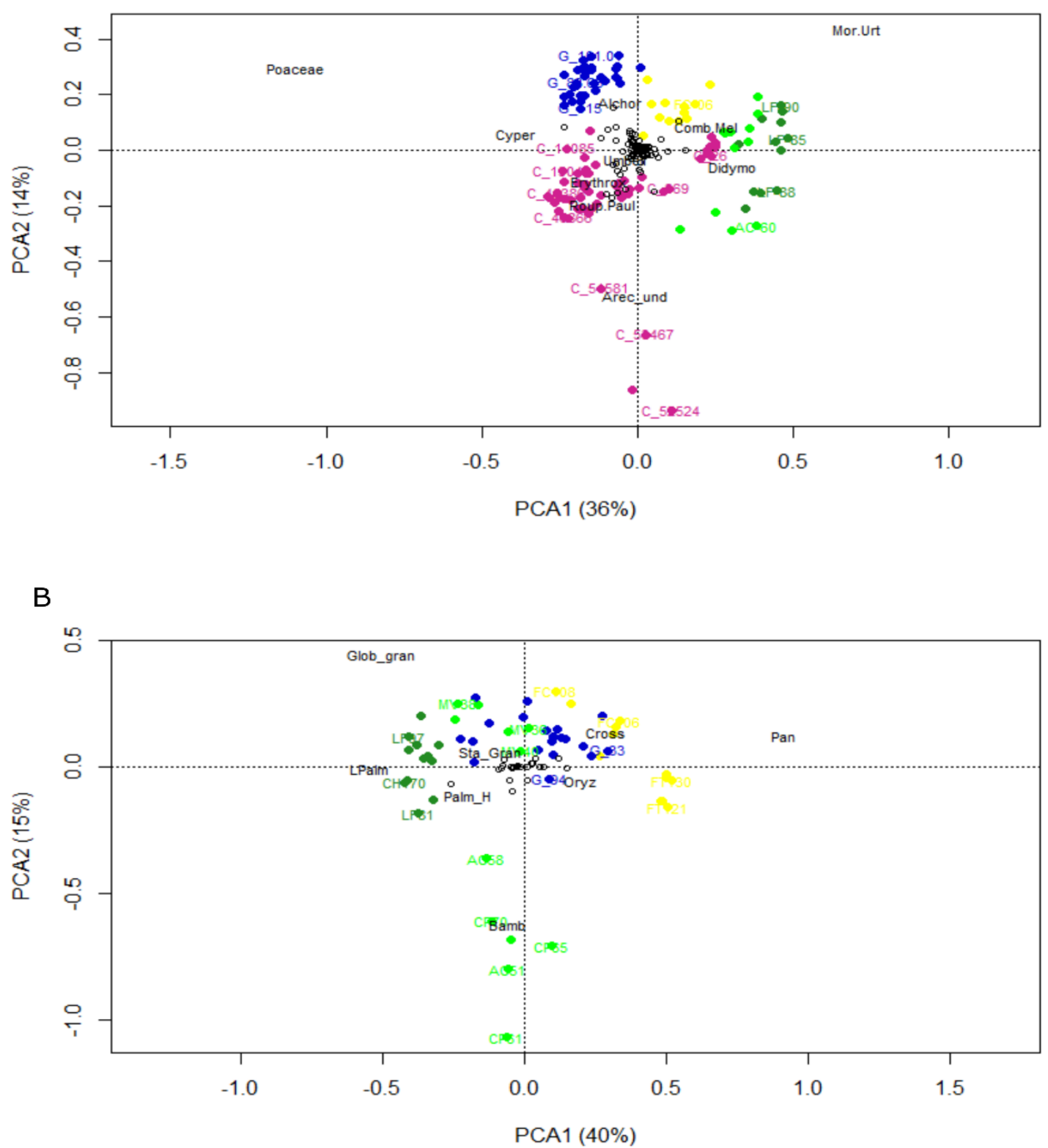

Figure 3 - Principal Component Analysis (PCA) biplots for modern and fossil samples. Panel A modern samples from NKMNP plots, fossil samples from Laguna Granja and Laguna Chaplin. Panel B - modern samples from NKMNP plots and fossil samples from Laguna Granja. Colours represent sample location: evergreen forest plots from NKMNP are coloured dark green; dry forest plots from NKMNP are light green; savannah plots from NKMNP are yellow; fossil samples from Laguna Chaplin are violet; fossil samples from Laguna Granja are dark blue. 

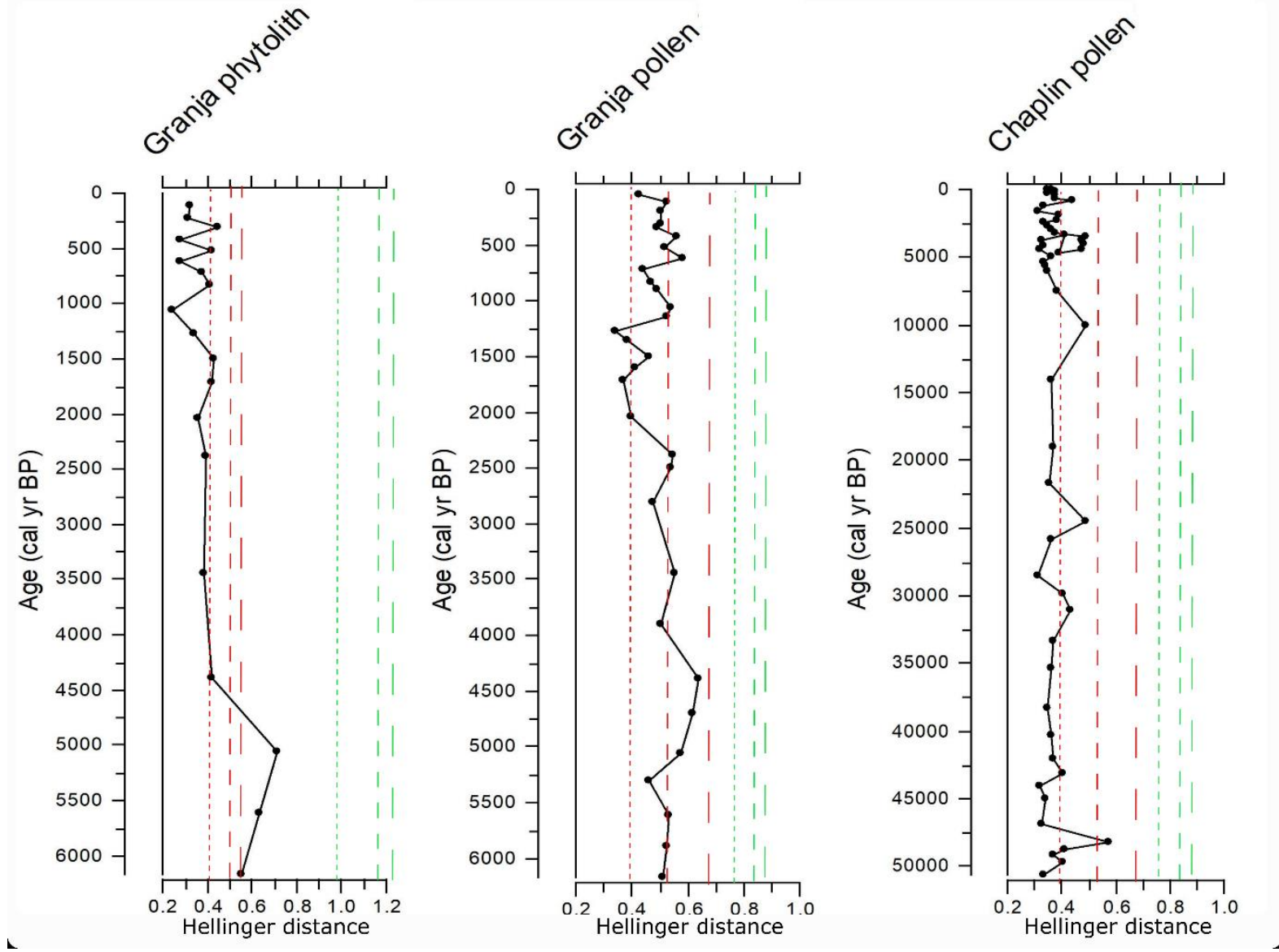

Figure 4 - Stratigraphic plots of Hellinger distances between pairwise assemblages downcore at Laguna Granja (phytoliths and pollen) and Laguna Chaplin (pollen). Age-depth models taken from original papers (Burbridge et al., 2004; Carson et al., 2015). Red dashed lines represent thresholds for floristic change within the ecosystem: lower quartile (Q1), median (Q2) and upper quartile (Q3) of Hellinger distances for the appropriate ecosystem and proxy, calculated based on modern distances between samples in vegetation study plots at Noel Kempff Mercado National Park (NKMNP) (Table 2). For Granja phytoliths, the thresholds for evergreen forest are plotted. For Granja and Chaplin pollen, the thresholds for savannah are plotted. Green dashed lines represent thresholds for ecosystem turnover: lower quartile (Q1), median (Q2) and upper quartile (Q3) of Hellinger distances for the turnover between evergreen forest and savannah, for the appropriate proxy (Table 3).

Supplementary Figures S1-7 


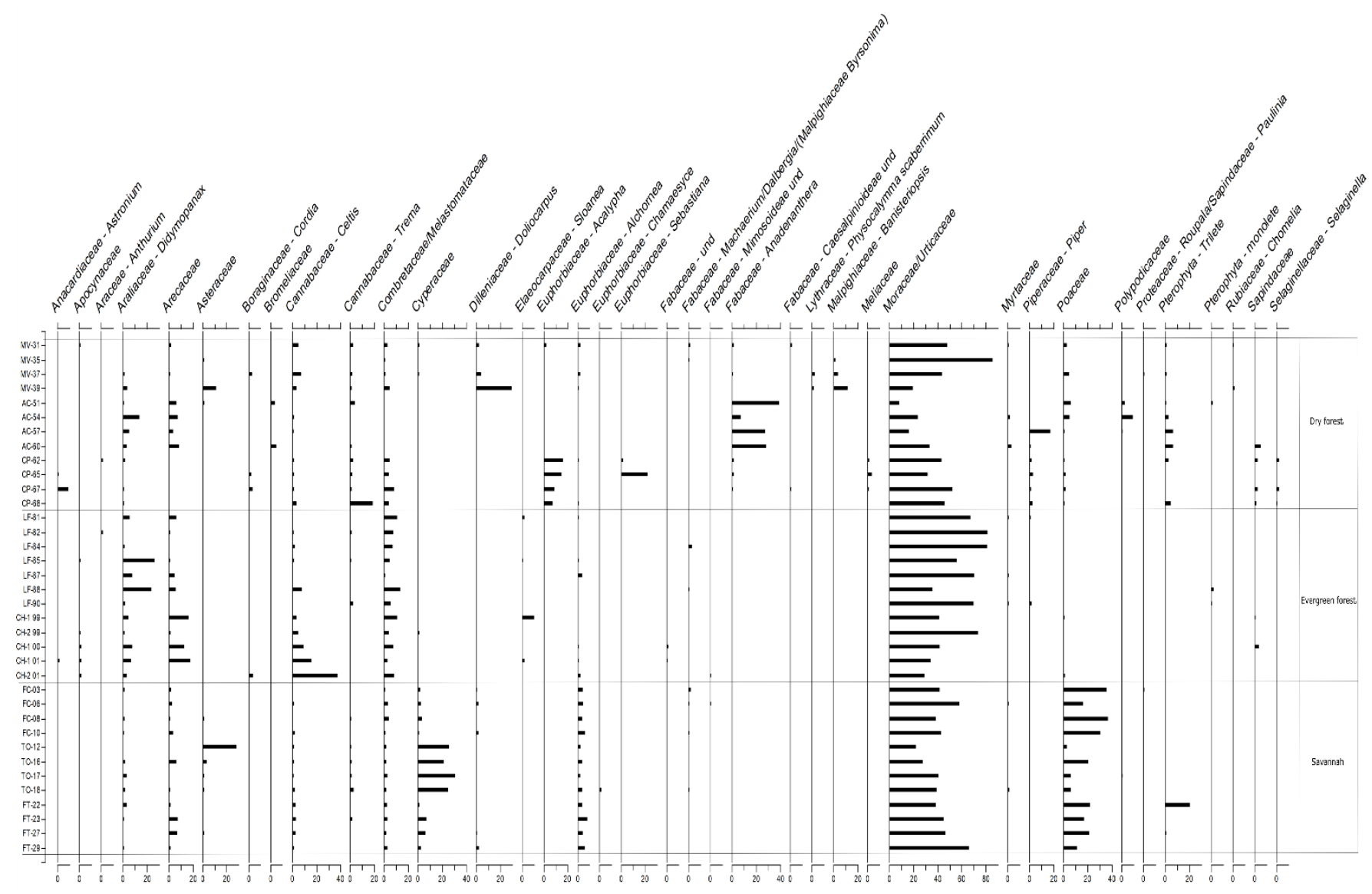

S1 - Summary diagram of modern pollen assemblages from plots within Noel Kempf Mercado National Park (NKMNP). Taxa plotted are those that occur at $>1 \%$ abundance in 2 or more samples. $\mathrm{X}$-axis represents percentage abundance. Plots are grouped by ecosystem class: $\mathrm{MV}, \mathrm{AC}, \mathrm{CP}-\mathrm{dry}$ forest; LF, CH - evergreen forest; FC, FT, TO - savannah. For full descriptions and analysis of pollen assemblages see original publications (Gosling et al., 2005; Gosling et al., 2009; Jones et al., 2009; Burn et al., 2010; Jones et al., 2011).

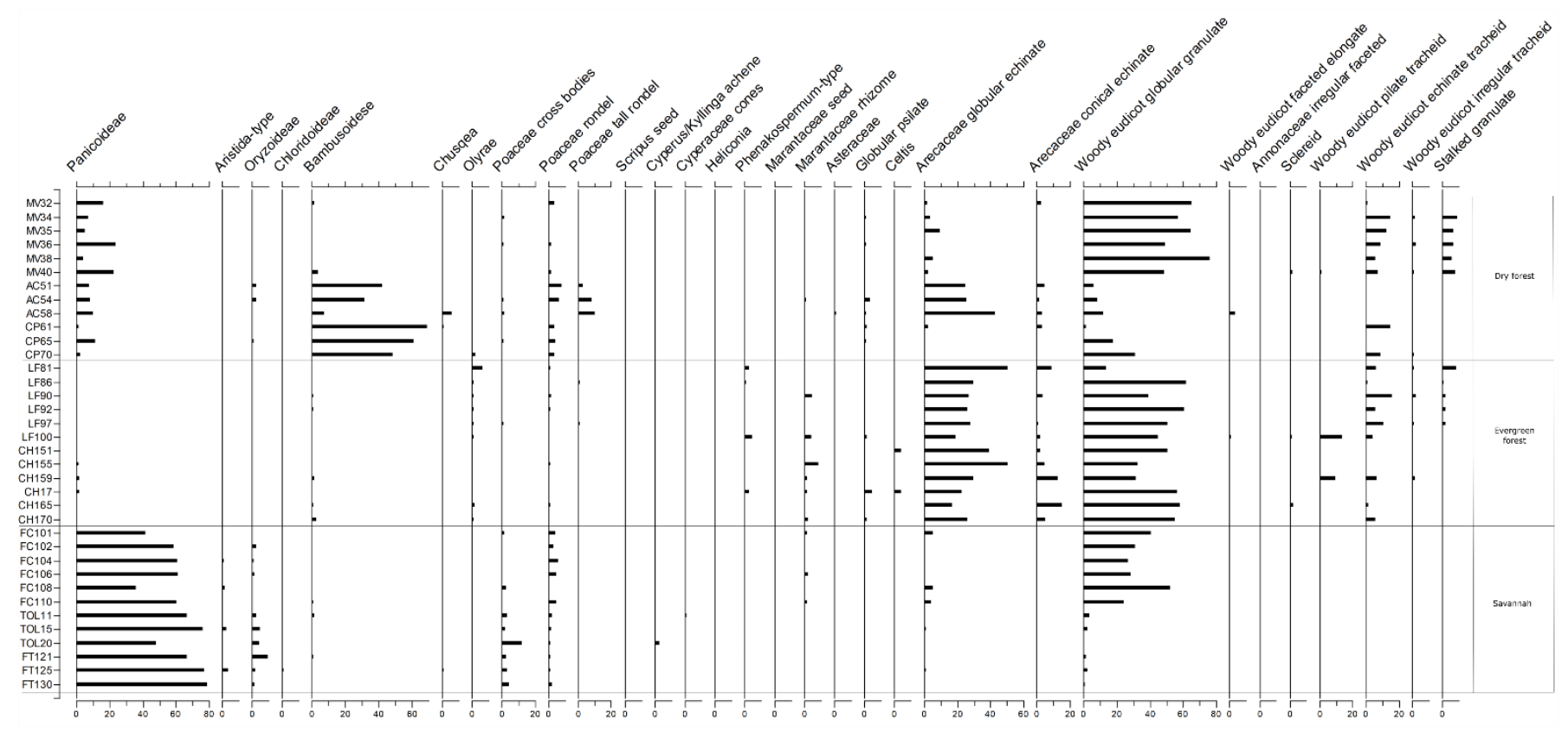


S2 - Summary diagram of modern phytolith assemblages from plots within Noel Kempf Mercado National Park (NKMNP). Taxa plotted are those that occur at $>1 \%$ abundance. X-axis represents percentage abundance. Plots are grouped by ecosystem class: MV, AC, CP - dry forest; LF, CH evergreen forest; FC, FT, TO - savannah. For full descriptions and analysis of phytolith assemblages see original publication (Dickau et al., 2013).

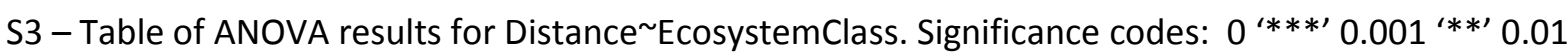
'*' 0.05 '? $0.1 " 1$.

\begin{tabular}{|l|l|l|l|l|l|}
\hline & Df & Sum Sq & Sq & F Value & $\operatorname{Pr}(>\mathrm{F})$ \\
\hline $\begin{array}{l}\text { Ecosystem } \\
\text { Class }\end{array}$ & 2 & 3.901 & 1.9505 & 52.41 & $<2 \mathrm{e}-16^{* * *}$ \\
\hline Residuals & 195 & 7.257 & 0.0372 & & \\
\hline
\end{tabular}

S4 - Table of Tukeys HSD test results for Distance ${ }^{\sim}$ EcosystemClass at the $95 \%$ confidence level.

\begin{tabular}{|l|l|l|l|l|}
\hline Ecosystem Class & diff & Iwr & upr & P adj \\
\hline $\begin{array}{l}\text { Evergreen forest- } \\
\text { Dry forest }\end{array}$ & -0.2789007 & -0.3582125 & -0.19958885 & 0.0000000 \\
\hline $\begin{array}{l}\text { Savannah-Dry } \\
\text { forest }\end{array}$ & -0.3135789 & -0.3928907 & -0.23426706 & 0.0000000 \\
\hline $\begin{array}{l}\text { Savannah- } \\
\text { Evergreen forest }\end{array}$ & -0.0346782 & -0.1139900 & 0.04463363 & 0.5571915 \\
\hline
\end{tabular}

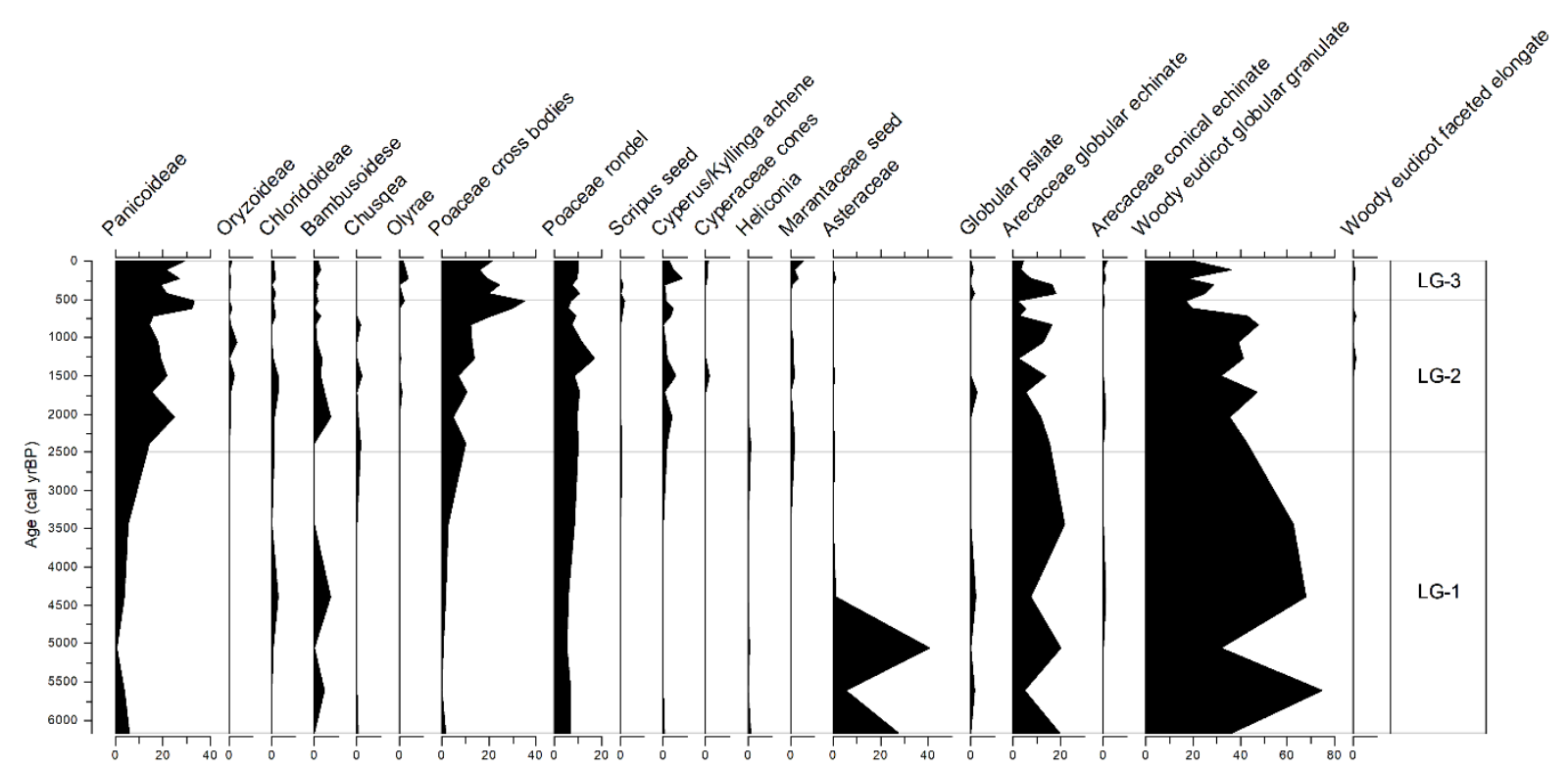

S5 - Summary diagram of fossil phytoliths from Laguna Granja, plotted against age of sediment in cal yrBP. Age-depth model taken from original publication (Carson et al., 2015). Taxa plotted are those that occur at $>1 \%$ abundance. $X$-axis represents percentage abundance. 


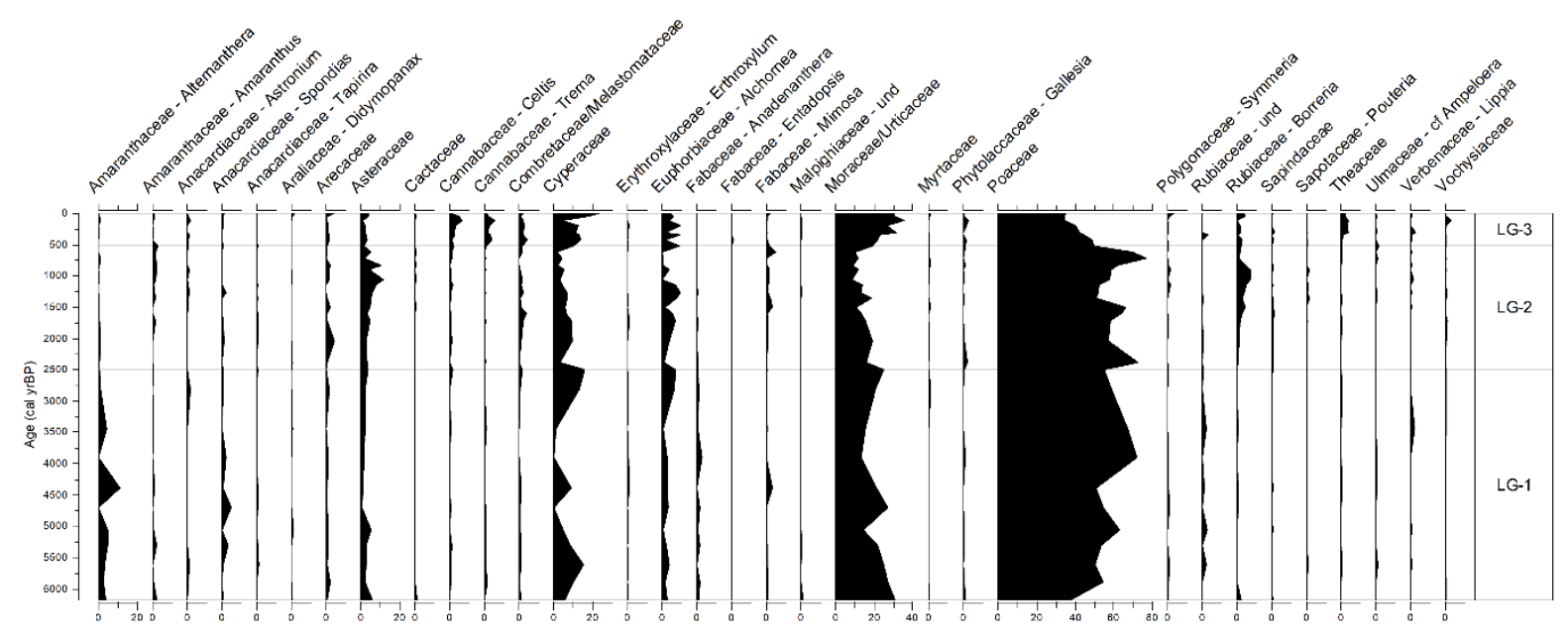

S6 - Summary diagram of fossil pollen from Laguna Granja, plotted against age of sediment in cal yrBP. Age-depth model taken from original publication (Carson et al., 2015). Taxa plotted are those that occur at $>1 \%$ abundance. $X$-axis represents percentage abundance.

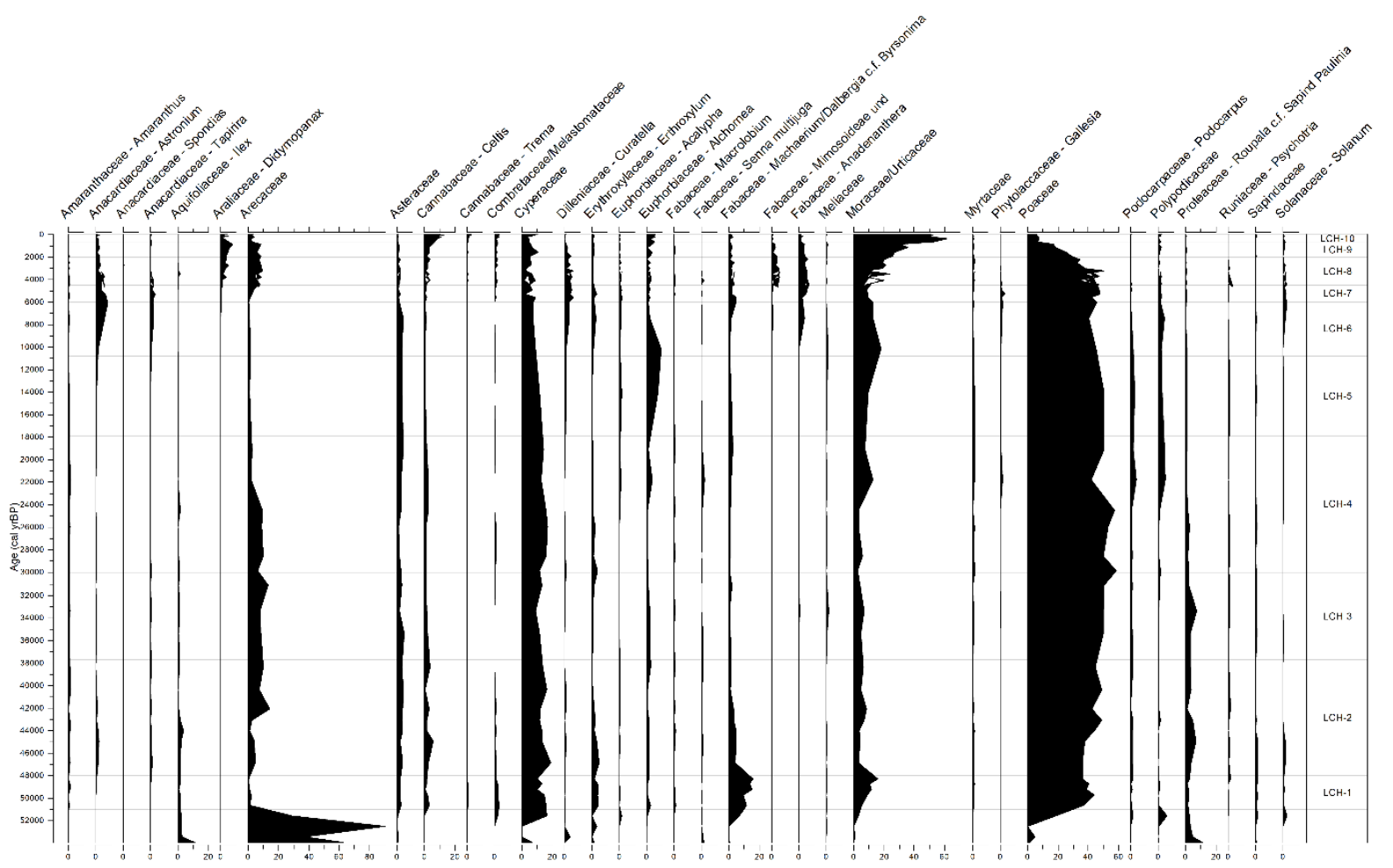

S7 - Summary diagram of fossil pollen from Laguna Chaplin, plotted against age of sediment in cal yrBP. Age-depth model taken from original publication (Burbridge et al., 2004). Taxa plotted are those that occur at $>1 \%$ abundance in 2 or more samples. $X$-axis represents percentage abundance. 